\title{
The interaction between sensory and tonic factors in the perception of the vertical in pigeons'
}

DAVID R. THOMAS AND JOSEPH LYONS

KENT STATE UNIVERSITY

In two separate experiments, 21 pigeons were given 10 days of training to peck a key on which a white vertical line was exposed. Next, the birds were given generalization tests along the angularity dimension with the floor tilted $24^{\circ}$ to the right or to the left. Reliable asymmetrical gradients were obtained with enhanced responding to the side toward which the floor was tilted. This posturally induced distortion in the visual perception of the vertical indicates that sensory-tonic interactions typically observed in humans have a parallel in this lower species

Witkin and Asch (1948), Werner, Wapner, and Chandler (1951) and others have observed that with small sidewise tilts of the body a luminescent line in the dark will be perceived as vertical when tilted an appropriate number of degrees opposite to body tilt. These latter investigators have further demonstrated that the extent of this overcompensation varies positively with amount of muscular involvement and degree of body tilt. Teuber and Mishkin (1954) have attempted to isolate the cortical mechanism responsible for this sensory-tonic interaction. They report that (human) patients with anterior lobe damage show greater overcompensatory errors than those with posterior damage who in turn are more inaccurate than normal controls. Errors similar to those produced by postural manipulation result when human Ss are tested with normal posture but with electrical stimulation of one side of the neck, or with a noise input to one ear (Wapner, Werner, \& Chandler, 1951).

The purpose of the present study was to determine if pigeons are also subject to a distortion in perception of the vertical as a result of experimental manipulations in posture, muscular involvement, etc. There is a rapidly accumulating body of literature on visual perception in pigeons and on the physiological mechanisms which may underly it. The development of a reliable technique to demonstrate sensory-tonic interactions in this species might constitute a useful contribution to this effort.

Fortunately, a simple and direct procedure for the study of the perception of the vertical in pigeons is available. Pigeons trained in an operant conditioning chamber to peck a key on which a white vertical line is projected will then yield a symmetrical decremental generalization gradient, responding most to the vertical line and progressively less to stimuli increasingly different from this value (çf. Butter, 1963; Honig,
Boneau, Burstein, \& Pennypacker, 1963; Newman \& Baron, 1965)。If training occurs with the floor in a normal position but generalization testing is done with the floor inclined sidewise, any error in the perception of the true vertical should be reflected in an asymmetry in the obtained generalization gradient, with the greatest response strength accruing to the stimulus subjectively perceived as vertical. Two separate experiments were performed according to this plan but with minor differences in test procedure.

Studies in humans in which posture is manipulated are typically performed with S's body and head restrained in a tilted position. In the present study the pigeons were tested while standing freely on a sidewise inclined plane. In this position the body is kept upright (or nearly so) but the S's weight distribution is altered to maintain balance. Any resulting distortion in visual perception is thus likely to be largely determined by the imbalance in muscular involvement required to maintain nearly erect posture.

\section{EXPERIMENT 1}

\section{Method}

Subjects. The Ss were 10 experimentally naive homing pigeons maintained at $70-75 \%$ of their ad lib weight throughout the experiment.

Apparatus. Two Grason-Stadler pigeon chambers were employed with associated automatic programming and recording equipment. Industrial Electronics Engineers In-Line display cells provided a white vertical line $1 / 8$-in. wide $\times 7 / 8$-in. high on a black background as well as lines with other inclinations. A GrasonStadler white noise generator, Model 901, supplied masking noise to both boxes at all times.

Procedure. . Following magazine and key-peck training with the vertical line stimulus, Ss were given two days of 50 continuous reinforcements each and then placed on a variable interval schedule with a mean interreinforcement interval of $1 \mathrm{~min}$. (VI-1). During all training the box was in darkness except for the stimulus light on the key. The Ss were given 10 daily $1 / 2-\mathrm{hr}$. sessions of VI-1 training and on the day following the last of these, they were tested in extinction for generalization on to five different angular orientations, $30^{\circ}, 60^{\circ}$, $90^{\circ}$ (the training stimulus), $120^{\circ}$ and $150^{\circ}$. These five stimuli were randomized in a series and six different random series were used with each stimulus presentation for $60 \mathrm{sec}$. On the test session the right side of the grid floor of the experimental chamber was elevated producing a $24^{\circ}$ tilt toward the left. Following 


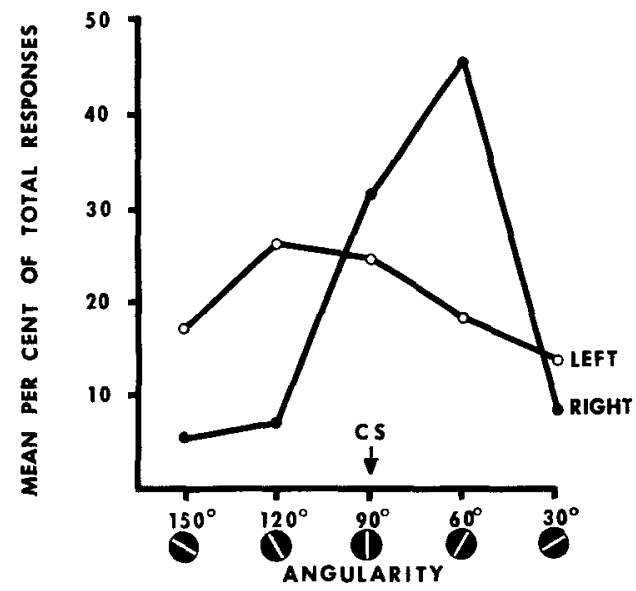

Fig. 1. Mean generalization gradients for all Ss in Experiment 1.

the generalization test, on the succeeding two days Ss were retrained with the floor in the usual (horizontal) position and on the next day they were retested for generalization in the same manner except that this time the floor was tilted $24^{\circ}$ to the right.

\section{Results}

In the analysis of generalization test performance, for each $S$ the measure used was the per cent of total responses made to each of the five test stimuli. The group means of these individual gradients on Tests 1 and 2 are presented in Fig. 1. The tilting of the floor in S's compartment produces a reliable asymmetry in the gradients with enhanced responding on the side toward which the floor is tilted. On both tests the difference between mean per cent of total responses to $60^{\circ}$ and $120^{\circ}$ is significant. For the floor tilt to the left: $t=3.24, d f=7, p<.01$. For the floor tilt to the right: $t=5.57, \mathrm{df}=6, \mathrm{p}<.01$. Two of the 10 original Ss failed to respond in $15 \mathrm{~min}$. of testing and were

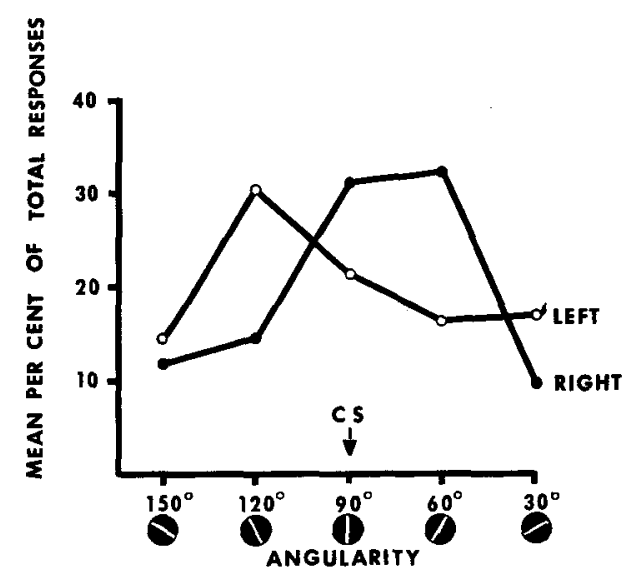

Fig. 2. Mean generalization gradients for all Ss in Experiment 2 . eliminated from Test 1 . One additional $\mathrm{S}$ which had responded on Test 1 was eliminated from Test 2 for the same reason. The average gradients of the group are typical of individual performance. Of the eight Ss completing Test 1 , seven showed greater responding to $120^{\circ}$ than to $60^{\circ}$. Of the seven Ss completing Test 2 , all showed greater responding to $60^{\circ}$ than to $120^{\circ}$.

Though the group mean gradient on each test shows the mode of responding displaced to a value $30^{\circ}$ from the true vertical, responding to $90^{\circ}$ is also strong suggesting that if intermediate stimulus values could have been sampled, the maximum response strength would accrue to a stimulus displaced more than $15^{\circ}$ but less than $30^{\circ}$ from vertical. Since the angle of the floor tilt was $24^{\circ}$, it appears that the pigeon does not compensate for the angle of the floor at all.

\section{EXPERIMENT 2}

\section{Method}

Subjects. The Ss in this experiment were 15 homing pigeons which had been used in an earlier experiment with wavelength stimuli but had never been exposed to a vertical line stimulus before.

Apparatus. The apparatus was the same as that used in Experiment 1.

Procedure. The Ss in this experiment were given 10 daily sessions of $1 / 2 \mathrm{hr}$. each to respond for VI-1 reinforcement to a pecking key on which a vertical line stimulus was projected. In this, as in the first experiment, the chamber was in darkness throughout training and testing procedures, with the exception of the stimuli on the key. On the day following the 10th VI session the Ss were tested for generalization in extinction as follows. Two experimental chambers were used; in one the floor was tilted $24^{\circ}$ to the right, in the other $24^{\circ}$, to the left. Two Ss were tested simultaneously (in the two boxes) for three test series (15 stimuli); then they switched chambers and were tested for three more series under the other floor tilt condition, then three more in the original chamber and finally three more in the other one. Half of the Ss were started in each chamber, providing counterbalancing which was absent in the first experiment.

\section{Results}

The data were treated in the same manner as in Experiment 1 with each $S$ yielding two gradients, one for each floor tilt condition. As Fig. 2 indicates, the results are the same as in Experiment 1. For the floor tilt to the left: $t=3.03, d f=12, p<.02$. For the floor tilt to the right: $t=4.08, d f=12, p<.01$. Two of the original $15 \mathrm{Ss}$ failed to respond in $15 \mathrm{~min}$. of testing and were eliminated from the study. When the floor was tilted toward the left, 11 of the 13 Ss completing the test responded more to $120^{\circ}$ than to $60^{\circ}$. With the floor tilted toward the right, $11 \mathrm{Ss}$ responded more to $60^{\circ}$ than to $120^{\circ}$. 


\section{DISCUSSION}

In Experiment 1, tilting the floor toward the right appeared to have had a greater effect than tilting it to the left. It should be remembered, however, that the right test was given subsequent to the left one, thus resulting in a steeper gradient as well as (possibly) in more sensitivity to postural effects. In Experiment 2, the floor tilt to the left was the more effective, thus there is no consistent evidence regarding differential sensitivity to tilt in the two directions corresponding to that reported for humans by Witkin and Asch (1948).

It is also important to emphasize that in these experiments the line on the key was the only source of light in a chamber which was otherwise completely dark. In pilot experiments in which the chamber was illuminated, there was no evidence of any systematic asymmetry in the generalization gradient correlated with the position of the floor. This suggests that the presence of a visual frame of reference dominates over the proprioceptive sense in influencing the perception of the vertical in the pigeon. A similar result has been reported for humans by Asch and Witkin (1948a, 1948b).

The distortion of the perception of the vertical in pigeons standing on a sidewise inclined plane apparently involves a failure to compensate for the floor position. With humans whose body is tilted the error is typically an overcompensation. The two test situations are basically different, however, and we knew of no available data from humans tested in a situation comparable to that employed here. To permit a cross-species comparison, 20 college students were tested in our laboratory for their ability to adjust a luminescent movable bar to a vertical position when standing on a $24^{\circ}$ sidewise inclined platform. Many trials were given with the floor tilted in each direction, and though the magnitude of the distortion was far less than for pigeons (i.e., approximately a one-degree average error) the direction of error was the same. The human Ss reliably perceived as vertical an inclination of the bar in the direction toward which the floor was also sloped. The procedure used and the data obtained in this (human) study will be reported in detail elsewhere at a later time.
Research currently underway in the laboratory with pigeons is concerned with the range of floor tilts over which this perceptual distortion occurs, with the perceptual after effects of training $\mathrm{Ss}$ on a tilted surface, and with the effects of presenting a distorted visual field while leaving posture unaltered. This program of research suggests that the procedure of utilizing the stimulus generalization gradient to reflect a variety of perceptual processes in sub-verbal organisms may constitute a fruitful tool for behavioral research involving phenomena heretofore inaccessible to scientific investigation.

\section{References}

Asch, S. E., \& Witkin, H. A. Studies in space orientation: I. Perception of the upright with displaced visual fields. J. exp. Psychol., 1948a, 38, 325-337.

Asch, S. E., \& Witkin, H. A. Studies in space orientation: II. Perception of the upright with displaced visual fields and with the body tilted. J. exp. Psychol., 1948b, 38, 455-477.

Butter, C. M. Stimulus generalization along one and two dimensions in pigeons. J. exp. Psychol., 1963, 65, 339-346.

Honig, W. K., Boneau, C. A., Burstein, K. R., \& Pennypacker, H. S. Positive and negative generalization gradients obtained after equivalent training conditions. J. comp. physiol. Psychol., $1963,56,111-116$.

Newman, F. L., \& Baron, M. R. Stimulus generalization along the dimension of angularity: A comparison of training procedures. J. comp. physiol. Psychol., 1965, 60, 59-63.

Teuber, H. L., \& Mishkin, M. Judgment of visual and postural vertical after brain injury. J. Psychol., 1954, 38, 161-175.

Wapner, S., Werner, H., \& Chandler, K. A. Experiments on sensorytonic field theory of perception: 1 . Effect of extraneous stimulation on the visual perception of verticality. J. exp. Psychol., $1951,42,341-345$.

Wemer, H., Wapner, S., \& Chandler, K. A. Experiments on sensorytonic field theory of perception: II. Effect of supported and unsupported tilt of the body on visual perception of verticality. J. exp. Psychol, 1951, 42, 346-350.

Witkin, H. A., \& Asch, S. E. Studies in space orientation: IV. Further experiments on perception of the upright with displaced visual fields. J. exp. Psychol., 1948, 38, 762-782.

\section{Note}

1. This research was supported by N. 1. H. grant RO 1 HD-0090305 , under the direction of the first author.

(Received in the Editorial Office January 23, 1966.) 